\title{
ANÁLISE DE CENÁRIOS PROSPECTIVOS: UM ESTUDO DO MERCADO BRASILEIRO DE PETRÓLEO
}

\author{
Camila Guimarães Monteiro de Freitas Alves \\ Universidade Federal Fluminense (UFF) \\ camila_gmf@hotmail.com \\ Danilo Colombo \\ Universidade Federal Fluminense (UFF) \\ colombo.danilo@hotmail.com
}

Pierre Morlin

Universidade Federal Fluminense (UFF)

pierremorlin@poli.ufrj.br

Carlos Francisco Simões Gomes

Universidade Federal Fluminense (UFF)

cfsg1@bol.com.br

\author{
Marcos dos Santos \\ Instituto Militar de Engenharia (IME) \\ Praça Gen. Tibúrcio, 80 - Urca, Rio de Janeiro - RJ, 22290-270 marcosdossantos_dou- \\ torado_uff@yahoo.com.br
}

\section{RESUMO}

A indústria mundial de petróleo se caracteriza por um mercado intercontinental, aumento da concorrência e de produtos substitutos, blocos tradicionalmente exportadores, uso intenso de tecnologia, países com alta demanda externa, novas áreas exploratórias e fluxos relevantes de importação e exportação se configurando nos últimos anos. Nesse contexto, novas oportunidades de explotação, exploração e produção surgem a cada instante, com maior ou menor expectativa de retorno ao longo do ciclo de vida dos investimentos. Neste sentido, a análise de cenários pode indicar lucros ou prejuízos enormes. O presente estudo busca analisar este horizonte a fim de indicar, baseado em cenários prospectivos, $\mathrm{o}$ planejamento de ações estratégicas para uma indústria petrolífera nacional, a Petróleo Brasileiro S.A. (Petrobras).

Palavra-chave: Indústria Petrolífera; Cenários; Prospectiva.

\begin{abstract}
The world oil industry is characterized by an intercontinental market, increased competition and substitute products, traditionally exporting blocks, intensive use of technology, countries with high external demand, new exploratory areas and relevant import and export flows in recent years.. In this context, new opportunities for exploration, exploitation and production appear at every moment, with greater or lesser expectation of return over the life cycle of investments. In this sense, scenario analysis can indicate huge profits or losses. The present study seeks to analyze this horizon in order to indicate, based
\end{abstract}


on prospective scenarios, the planning of strategic actions for a national oil industry, Petróleo Brasileiro S.A. (Petrobras).

Keywords: Oil industry; Scenarios; Foresight.

\section{Como Citar:}

ALVES, Camila Guimarães Monteiro de Freitas; COLOMBO, Danilo; MORLIN, Pierre; GO MES, Carlos Francisco Simões; SANTOS, Marcos dos. Proposta de Modelagem Híbrida PROMETHEE-SAPEVO-M1: avaliação multicritério de drones para emprego na guerra naval. In: SIMPÓSIO DE PESQUISA OPERACIONAL E LOGÍSTICA DA MARINHA, 19., 2019, Rio de Janeiro, RJ. Anais [...]. Rio de Janeiro: Centro de Análises de Sistemas Navais, 2019.

\section{INTRODUÇÃO}

O setor de petróleo existe há mais de 150 anos e possui grande importância para a sociedade. Destaca-se o desenvolvimento de diversos bens manufaturados cujos componentes derivam do petróleo e a utilização de petróleo no setor de transportes. $\mathrm{O}$ petróleo é uma variável que afeta a economia mundial, já que variações em seu preço podem causar crises ou incentivar economias.

Entretanto, a trajetória de preços do petróleo é sensível não somente a fatores econômicos, como outras commodities internacionais, mas também a diversos outros fatores. Portanto, este é um setor de grande desafio, tanto mundialmente, quanto para o Brasil e, com a recente queda de preços, adicionou-se incertezas para o setor.

Outro evento que afeta o futuro deste setor é a realização dos leilões do excedente da Cessão Onerosa e a definição de diretrizes para promoção da concorrência e atração de investimentos.

O setor de transportes também é um gerador de transformações nas perspectivas do setor e das indústrias que fazem parte do mesmo, tendo em vista a ampliação de serviços de transporte baseados em aplicativos digitais, aumento da oferta de veículos elétricos e surgimento dos veículos autônomos, entre outros fatores.

Assim, para minimizar essas mudanças, aproveitar as oportunidades e auxiliar na elaboração de estratégias nas organizações, a prospecção de cenários representa um recurso importante para analisar situações futuras. A partir de então é possível tomar decisões avaliando-se as incertezas e preparando-se para enfrentar os desafios que podem provocar grande impacto na atuação das organizações.

Elaborar cenários não é um exercício de predição e nem sinônimo de adivinhação, mas um empenho de fazer descrições admissíveis de situações futuras possíveis, buscando-se informações sobre prospecções futuras, analisando-se os fatores importantes às decisões que precisam ser tomadas.

Diante das diversas incertezas presentes no cenário de petróleo, este artigo tem como objetivo identificar os cenários possíveis, e dentre estes o desejável, o indesejável e o de tendência, de uma empresa petrolífera nacional.

Sendo assim, a partir de variáveis endógenas e exógenas, foram traçados cenários alternativos que auxiliem a identificar os principais desafios que deverão ser superados ao longo do tempo. 


\section{SPOLM2O19}

XIX SIMPÓSIO DE PESQUISA OPERACIONAL E LOGISTICA DA MARINHA RIO DE JANEIRO, RJ, BRASIL - 06 A 08 DE NOVEMBRO DE 2019

\section{REVISÃO BIBLIOGRÁFICA}

\subsection{CENÁRIOS PROSPECTIVOS}

De acordo com Marcial e Grumbach (2002), foi Gaston Berger, em sua obra: A atitude prospectiva, de 1957, quem criou a palavra "prospectiva", visando apresentar a necessidade de uma visão voltada para o futuro em uma época em que era comum usar a palavra "previsão", que tem um sentido de profecia.

Segundo Amer, Diam e Jetter (2013) a prospecção de cenários é um processo estratégico cada vez mais aplicado em diversos contextos. Reis, Vincenzi e Pupo (2016) destacam que a questão não é sobre utilizar ou não técnicas formais de prospecção, mas de que forma e quais técnicas devem ser usadas.

Conforme Cairns e Wright (2018) o planejamento de cenários foi criado visando ajudar os tomadores de decisão a trabalhar em ambientes complexos.

De acordo com Rohrbeck, Battistella e Huizingh (2015) o planejamento de cenários permite aos tomadores de decisão enxergar um conjunto mais amplo de possibilidades e, assim, ajudar organizações a se tornarem mais adaptáveis e antecipadoras.

A prospecção de cenários é uma ferramenta importante para os gestores, pois permite tomar decisões mais fundamentadas com relação ao futuro, embasado em evidências do presente e passado. Destaca-se a existência de incertezas no ambiente empresarial, dentre estas tem-se os fatores econômicos, ambientais, sociais, governamentais, entre outros, os quais encontram-se em constante mudança. Sendo assim, para que uma organização seja competitiva, a mesma precisa traçar seu planejamento estratégico com base em prospecções de cenários (BLOIS et al, 2018).

Segundo Witt, Dumeier e Geldermann (2020) a integração do planejamento de cenários permite uma investigação sistemática de incertezas externas.

O planejamento de cenários prospectivos representa possíveis futuros e, possibilita delinear as capacidades para enfrentar os desafios apresentados pelo conjunto de cenários. Considera-se que o conjunto de cenários escolhido é suficientemente representativo dos futuros possíveis (DOBIAS; EISLER, 2018).

Por meio do planejamento de cenários são identificados os desafios do futuro e, a partir de decisão estratégica, verifica-se o futuro desejado. Neste sentido, a aplicação do método de cenários prospectivos leva a elaboração de estratégias que indicam os objetivos da organização no futuro e, caso não as sigam, tendem a ficar fora do mercado (AZEVEDO; ARAÚJO; DUARTE, 2017).

Segundo Assis et al (2017) as ações estratégicas deliberadas a partir da previsão de cenários prospectivos auxiliam os decisores a minimizar os riscos de acontecimentos futuros.

A partir da análise das possibilidades de futuro, apreciam-se as implicações de cada um dos cenários possíveis, identificando oportunidades e ameaças (ALMEIDA; MARICATO, 2015). Segundo Barrizonte et al (2015) por meio dos cenários prospectivos é possível desenvolver estratégias que possibilitam antecipar os problemas das instituições.

Diante as possibilidades dos cenários, Godet (1993) faz a distinção de três tipos: o cenário de referência, que indica o cenário mais provável; o cenário contrastado, que corresponde ao cenário realizável; e o cenário desejável, como o cenário possível e não necessariamente realizável.

De acordo com Schwartz (2003) deve-se escolher de três a cinco futuros mais representativos para que a organização construa as condições necessárias para aprender sobre o futuro e suas várias possibilidades. O autor destaca que um único cenário imobiliza a organização em torno de solução única, o que dificulta a reação caso o "previsto" não aconteça. 
A metodologia utilizada para o desenvolvimento deste artigo é baseada no estudo de Gomes e Costa (2013) como base para construção e análise dos cenários prospectivos. Os autores criaram uma abordagem para análise de cenários denominada Momentum, a qual é estruturada em sete etapas:

1) Visão geral do sistema ou negócio selecionado, determinando suas entradas, resultados, missão e visão de futuro, quando aplicável;

2) mapeamento dos atores relevantes e suas respectivas influências, identificação de variáveis, selecionando as internas (pontos fortes e fracos) e as variáveis externas (ameaças e oportunidades) e realização da análise SWOT;

3) avaliações de incertezas e seus respectivos fatores causais;

4) seleção de variáveis relevantes;

5) elaboração de variáveis com análise histórica, para definir configurações e atribuir suas respectivas probabilidades de ocorrências

6) definir indicadores-chave e realizar suas análises retrospectivas;

7) construção de cenários, buscando o mais desejável e os cenários que são pertinentes.

Diversos estudos de canários prospectivos foram realizados a partir deste método. Vieira et al (2014) analisaram o cenário brasileiro de etanol. Já Cavalcanti, Costa Junior e Gomes (2016) realizaram um estudo sobre uma microempreendedora no ramo de doces em Niterói-RJ. Assis et al (2017) avaliaram os cenários prospectivos na aviação comercial brasileira. Andrade e Gomes (2017) desenvolveram cenários prospectivos para o setor da construção civil no Brasil e no Rio de Janeiro. Sanseverino, Gomes e Barcelos (2018) analisaram os cenários para uma universidade pública.

\subsection{SETOR BRASILEIRO DE PETRÓLEO}

Conforme divulgado pelo Ministério de Minas e Energia - MME (2019a) as ações prioritárias para o setor de petróleo e gás natural são:

i) realização do leilão do excedente da Cessão Onerosa;

ii) continuidade do calendário plurianual de rodadas de licitações;

iii) apoio às medidas legislativas e regulatórias para abertura do mercado, atração de investimentos e aumento da competição no setor de gás natural;

iv) desenvolvimento sinérgico dos setores de gás natural e de energia elétrica;

v) atração de investimentos em refino e logística;

vi) avaliação de alternativas para equalizar os preços de gás liquefeito de petróleo (GLP);

vii) combate à sonegação e à adulteração de combustíveis.

Como principal ação, destaca-se o acordo entre o Governo Federal e a Petrobras sobre a revisão do contrato da Cessão Onerosa, assinado entre as partes em 2010. Neste sentido, Conselho Nacional de Política Energética (CNPE) vem publicando resoluções que versam sobre as diretrizes para a realização do Leilão do Excedente da Cessão Onerosa.

Destaca-se que a Petrobras manifestou interesse em exercer o direito de preferência em diversos blocos (PETROBRAS, 2019). Entretanto, ressalta-se o aumento do número de empresas inscritas na Oferta Permanente, as quais apresentaram declaração de interesse (ANP, 2019).

Espera-se que com a realização desses certames e a alta produtividade dos campos do Pré-sal haja a ampliação da competitividade do Brasil na atração de investimentos na indústria de óleo e gás.

Outro ponto a ser destacado que influencia o setor é a edição da Resolução CNPE $n^{\circ}$ 9/2019, a qual estabeleceu diretrizes para a promoção da livre concorrência na atividade de refino no Brasil, incluindo a recomendação de alienação completa dos ativos do Programa 
de Parcerias e Desinvestimentos da Petrobras. O alienante não pode ter participação societária nos empreendimentos de operação de venda (CNPE, 2019).

No que diz respeito ao setor de abastecimento, o MME anunciou a criação do programa Abastece Brasil, que tem por objetivo promover a concorrência, atrair investimentos em refino e logística e combater a sonegação e a adulteração de combustíveis (MME, 2019b).

\section{CENÁRIOS PROSPECTIVOS DO PETRÓLEO}

\subsection{ATORES}

Com análise do setor, foi possível identificar os principais atores envolvidos. De acordo com o Relatório "Desafios do estado brasileiro no desenvolvimento do setor de óleo e gás” do Tribunal de Contas da União (2018), foram definidos oito principais clusters de desafios que precisam ser superados para o pleno desenvolvimento do setor de petróleo e gás natural no Brasil. A partir desses clusters, apresentam-se os atores que influenciam no mesmo na Tabela 1.

Tabela 1 - Atores envolvidos por cluster

\begin{tabular}{|c|c|}
\hline Cluster & Atores envolvidos \\
\hline Ambiente regulatório & $\begin{array}{l}\text { Agência Nacional do Petróleo, Gás Natural e Biocombustíveis } \\
\text { (ANP); } \\
\text { Centro Brasileiro de Infraestrutura (CBIE); } \\
\text { Controladoria-Geral da União (CGU); } \\
\text { Empresa de Pesquisa Energética (EPE); Ministério de Minas e } \\
\text { Energia (MME); } \\
\text { Organização Nacional da Indústria do Petróleo (ONIP); } \\
\text { Programa de Parcerias de Investimentos (PPI). }\end{array}$ \\
\hline Campos Maduros & $\begin{array}{l}\text { Agência Nacional do Petróleo, Gás Natural e Biocombustíveis } \\
\text { (ANP); } \\
\text { Organização Nacional da Indústria do Petróleo (ONIP). }\end{array}$ \\
\hline Cessão Onerosa & $\begin{array}{l}\text { Agência Nacional do Petróleo, Gás Natural e Biocombustíveis } \\
\text { (ANP); } \\
\text { FGV ENERGIA; } \\
\text { Ministério de Minas e Energia (MME); } \\
\text { Organização Nacional da Indústria do Petróleo (ONIP); } \\
\text { Programa de Parcerias de Investimentos (PPI); } \\
\text { Pré-Sal Petróleo S.A. (PPSA). }\end{array}$ \\
\hline Conteúdo Local & $\begin{array}{l}\text { Controladoria-Geral da União (CGU); } \\
\text { Instituto Brasileiro de Petróleo, Gás e Biocombustíveis (IBP); } \\
\text { Organização Nacional da Indústria do Petróleo (ONIP); } \\
\text { Programa de Parcerias de Investimentos (PPI). }\end{array}$ \\
\hline $\begin{array}{l}\text { Desinvestimento da } \\
\text { Petrobras }\end{array}$ & $\begin{array}{l}\text { Controladoria-Geral da União (CGU); } \\
\text { Ministério de Minas e Energia (MME). }\end{array}$ \\
\hline $\begin{array}{l}\text { Gestão de Contratos } \\
\text { de Partilha, } \\
\text { Individualização da } \\
\text { Produção e } \\
\text { Comercialização do }\end{array}$ & $\begin{array}{l}\text { Controladoria-Geral da União (CGU); } \\
\text { Pré-Sal Petróleo S.A. (PPSA). }\end{array}$ \\
\hline
\end{tabular}




\begin{tabular}{|c|l|}
\hline Óleo da União & \\
\hline \multirow{2}{*}{$\begin{array}{c}\text { Mercado de Refino e e } \\
\text { Distribuição }\end{array}$} & $\begin{array}{l}\text { Agência Nacional do Petróleo, Gás Natural e Biocombustíveis } \\
\text { Empresa de Pesquisa Energética (EPE); } \\
\text { FGV ENERGIA; } \\
\text { Instituto Brasileiro de Petróleo, Gás e Biocombustíveis (IBP); } \\
\text { Organização Nacional da Indústria do Petróleo (ONIP) }\end{array}$ \\
\hline $\begin{array}{l}\text { Agência Nacional do Petróleo, Gás Natural e Biocombustíveis } \\
\text { (ANP); }\end{array}$ \\
$\begin{array}{l}\text { Previsibilidade do } \\
\text { Empresa de Pesquisa Energética (EPE); } \\
\text { Instituto Brasileiro de Petróleo, Gás e Biocombustíveis (IBP); } \\
\text { Programa de Parcerias de Investimentos (PPI). }\end{array}$ \\
\hline
\end{tabular}

Além desses atores, podem-se citar os seguintes:

- BNDES, que fomenta o desenvolvimento econômico e social do Brasil por meio dos empréstimos realizados;

- IBAMA, órgão que resguarda o meio ambiente brasileiro, evitando impactos significativos nesta área;

- Fornecedores;

- Clientes, que influenciam na maior oferta de produtos derivados do petróleo;

- Acionistas, que visam obter maiores retornos sobre seus investimentos;

- Empresas inscritas na Oferta Permanente.

\subsection{DEFINIÇÃO DE VARIÁVEIS E INDICADORES}

\subsubsection{Avaliando-se o ambiente interno da empresa}

Pontos Fortes:

- A - Viabilidade técnica da exploração do pré-sal: medida através do percentual de sucesso exploratório, ou seja, na porcentagem de poços perfurados em que se encontrou petróleo. Este indicador é divulgado pelo IBP (Instituto Brasileiro de Petróleo, Gás e Biocombustíveis)

\begin{tabular}{|l|l|l|}
\hline $\mathbf{2 0 1 3}$ & $\mathbf{2 0 1 4}$ & $\mathbf{2 0 1 5}$ \\
\hline $100 \%$ & $85 \%$ & $86 \%$ \\
\hline
\end{tabular}

Tabela 2 - Percentual de sucesso exploratório

O último relatório emitido pelo IBP foi em 2016, por isso não há valores mais recentes

- B - Investimento em P\&D: a pesquisa e desenvolvimento de tecnologias é um diferencial competitivo na exploração em águas ultra profundas, viabilizando a exploração de diversos campos a baixos custos. O investimento em P\&D é divulgado em bilhões de US\$ no Relato Integrado da Petrobras

\begin{tabular}{|c|c|c|c|}
\hline $\mathbf{2 0 1 5}$ & $\mathbf{2 0 1 6}$ & $\mathbf{2 0 1 7}$ & $\mathbf{2 0 1 8}$ \\
\hline 2,024 & 1,826 & 1,831 & 2,3 \\
\hline
\end{tabular}

Tabela 3 - Investimento em P\&D 
- F - Reservas da Petrobras: Medida do volume de reservas da Petrobras em bilhões de barris de óleo equivalente, divulgado no Relato Integrado da Petrobras. A empresa deve buscar a gestão dos reservatórios e a participação em novos contratos de exploração e produção, em busca de uma contínua incorporação de reservas

\begin{tabular}{|l|l|l|l|}
\hline $\mathbf{2 0 1 5}$ & $\mathbf{2 0 1 6}$ & $\mathbf{2 0 1 7}$ & $\mathbf{2 0 1 8}$ \\
\hline 10,516 & 9,672 & 9,752 & 9,606 \\
\hline
\end{tabular}

Tabela 4 - Volume de reservas da Petrobras (em bilhões de barris de óleo equivalente)

- H - Relacionamento com o Mercado: Medida pelo número de fornecedores que a empresa transacionou, medido em milhares de fornecedores, divulgado no Relato Integrado da Petrobras. A cadeia de fornecedores é fundamental para o desenvolvimento de grandes projetos, como os do pré-sal.

\begin{tabular}{|c|c|c|c|}
\hline $\mathbf{2 0 1 5}$ & $\mathbf{2 0 1 6}$ & $\mathbf{2 0 1 7}$ & $\mathbf{2 0 1 8}$ \\
\hline 13 & 10,7 & 11 & 12,7 \\
\hline
\end{tabular}

Tabela 5 - Número de fornecedores que a Petrobras transacionou (em milhares de fornecedores)

- I - Capacidade de Investimento: Medida em volume investido em bilhões de reais, divulgado no Relato Integrado da Petrobras. Grande parte deste investimento é voltada para o desenvolvimento da produção de novos campos de petróleo, prioritariamente no polo pré-sal da Bacia de Santos.

\begin{tabular}{|l|l|l|l|}
\hline $\mathbf{2 0 1 5}$ & $\mathbf{2 0 1 6}$ & $\mathbf{2 0 1 7}$ & $\mathbf{2 0 1 8}$ \\
\hline 76,32 & 55,35 & 48,22 & 49,37 \\
\hline
\end{tabular}

Tabela 6 - Volume investido ( $m$ bilhões de reais)

- L - Custo de Extração: Medido em US\$/boe (barril de óleo equivalente), divulgado no Relato Integrado. O custo de extração impacta a viabilidade econômica de desenvolvimento de novos campos.

\begin{tabular}{|c|c|c|c|}
\hline $\mathbf{2 0 1 5}$ & $\mathbf{2 0 1 6}$ & $\mathbf{2 0 1 7}$ & $\mathbf{2 0 1 8}$ \\
\hline 11,7 & 10,3 & 11 & 10,7 \\
\hline
\end{tabular}

Tabela 7 - Custo de Extração (em US\$/barril de óleo equivalente)

\section{Fraquezas:}

- C - Segurança Ocupacional: Medida pela Taxa de Acidentes Registráveis (TAR), indicador da indústria que mede todos os tipos acidentes e incidentes ocorridos por milhão de homens hora, divulgada no Relato Integrado da Petrobras. A redução do TAR é uma das metas de topo da presidência da companhia e impacta nos custos com acidentes de trabalho, impacta na imagem da empresa e na continuidade operacional das instalações. Caso a empresa deseje expandir seus investimentos e suas atividades, deve-se manter controle nesta variável para que não seja um efeito colateral

\begin{tabular}{|l|l|l|l|}
\hline $\mathbf{2 0 1 5}$ & $\mathbf{2 0 1 6}$ & $\mathbf{2 0 1 7}$ & $\mathbf{2 0 1 8}$ \\
\hline 2,15 & 1,63 & 1,08 & 1,01 \\
\hline
\end{tabular}

Tabela 8 - Taxa de Acidentes Registráveis (TAR)

- D - Segurança de Processo: Medida pelo volume vazado de petróleo e derivados em metros cúbicos, divulgado no Relato Integrado. $\mathrm{O}$ volume vazado tem sérios impactos na continuidade operacional das plantas (poços, plataformas, refinarias, etc.) da 
companhia, pode prejudicar a imagem da mesma e também acarretar em pesadas multas ou perdas de licença ambiental

\begin{tabular}{|l|l|l|l|}
\hline $\mathbf{2 0 1 5}$ & $\mathbf{2 0 1 6}$ & $\mathbf{2 0 1 7}$ & $\mathbf{2 0 1 8}$ \\
\hline 71,6 & 51,9 & 35,8 & 18,5 \\
\hline
\end{tabular}

Tabela 9 - Volume vazado de petróleo e derivados (em metros cúbicos)

- E - Meio Ambiente: Medida pela emissão de gases de efeito estufa em milhões de toneladas de $\mathrm{CO} 2$ equivalentes, divulgado no Relato Integrado. O impacto das atividades de exploração e produção sobre o meio ambiente tem cada vez mais influência da demanda por outras fontes de energia e impacta o relacionamento social da empresa e com os órgãos reguladores

\begin{tabular}{|l|l|l|l|}
\hline $\mathbf{2 0 1 5}$ & $\mathbf{2 0 1 6}$ & $\mathbf{2 0 1 7}$ & $\mathbf{2 0 1 8}$ \\
\hline 78,2 & 66,5 & 67,1 & 61,7 \\
\hline
\end{tabular}

Tabela 10 - Emissão de gases de efeito estufa (em milhões de toneladas de CO2 equivalentes)

- G - Saúde Financeira: Medida pela dívida líquida em bilhões de R\$, divulgado no Relato Integrado. A redução da dívida líquida é uma das metas de topo da presidência da companhia, aumentando a capacidade da companhia a buscar novos investimentos.

\begin{tabular}{|l|l|l|l|}
\hline $\mathbf{2 0 1 5}$ & $\mathbf{2 0 1 6}$ & $\mathbf{2 0 1 7}$ & $\mathbf{2 0 1 8}$ \\
\hline 392,1 & 314,1 & 280,8 & 268,9 \\
\hline
\end{tabular}

Tabela 11 - Dívida líquida (em bilhões de R\$)

\subsubsection{Avaliando-se 0 ambiente externo}

Oportunidades:

- M - Reservas Provadas de Petróleo no Brasil: Medida em bilhões de barris de petróleo nas reservas provadas em território nacional, divulgada pelo BP Statistical Review of World Energy

\begin{tabular}{|l|l|l|l|l|l|}
\hline $\mathbf{2 0 1 3}$ & $\mathbf{2 0 1 4}$ & $\mathbf{2 0 1 5}$ & $\mathbf{2 0 1 6}$ & $\mathbf{2 0 1 7}$ & $\mathbf{2 0 1 8}$ \\
\hline 15,6 & 16,2 & 13 & 12,6 & 12,8 & 13,4 \\
\hline
\end{tabular}

Tabela 12 - Reservas Provadas de Petróleo no Brasil (em bilhões de barris de petróleo)

- O - Capacidade Efetiva de Refino no Brasil: Medida da capacidade total efetiva de refino no país em milhares de barris por dia, divulgada pela BP Statistical Review of Word Energy

\begin{tabular}{|l|l|l|l|l|l|}
\hline $\mathbf{2 0 1 3}$ & $\mathbf{2 0 1 4}$ & $\mathbf{2 0 1 5}$ & $\mathbf{2 0 1 6}$ & $\mathbf{2 0 1 7}$ & $\mathbf{2 0 1 8}$ \\
\hline 2,097 & 2,238 & 2,281 & 2,289 & 2,285 & 2,285 \\
\hline
\end{tabular}

Tabela 13 - Capacidade total efetiva de refino no país (em milhares de barris por dia) 
- Q- Exportação Brasileira de Petróleo: Medida da quantidade de petróleo exportada pelo Brasil em barris equivalente de petróleo no ano, divulgada pela ANP

\begin{tabular}{|l|l|l|l|l|l|}
\hline $\mathbf{2 0 1 3}$ & $\mathbf{2 0 1 4}$ & $\mathbf{2 0 1 5}$ & $\mathbf{2 0 1 6}$ & $\mathbf{2 0 1 7}$ & $\mathbf{2 0 1 8}$ \\
\hline 138.977 .409 & 189.401 .385 & 268.910 .391 & 291.357 .120 & 363.747 .541 & 410.009 .540 \\
\hline \multicolumn{5}{|c|}{ Tabela 14 Quantidade de petróleo exportada pelo Brasil } \\
(em barris equivalente de petróleo no ano)
\end{tabular}

- S - Crescimento Econômico do Brasil: Medida pela variação real do PIB (Produto Interno Bruto) brasileiro, divulgado pelo IBGE (Instituto Brasileiro de Geografia e Estatística)

\begin{tabular}{|c|c|c|c|c|c|}
\hline $\mathbf{2 0 1 3}$ & $\mathbf{2 0 1 4}$ & $\mathbf{2 0 1 5}$ & $\mathbf{2 0 1 6}$ & $\mathbf{2 0 1 7}$ & $\mathbf{2 0 1 8}$ \\
\hline 3,0 & 0,5 & $-3,5$ & $-3,3$ & 1 & 1,1 \\
\hline
\end{tabular}

Tabela 15 - Variação real do PIB (Produto Interno Bruto)

Ameaças:

- J - Preço do Petróleo: Preço bruto do crude de referência, tipo brent, em dólares por barril divulgados pela ANP. O preço do petróleo influencia na atratividade financeira do aumento da produção e das reservas.

\begin{tabular}{|l|l|l|l|l|}
\hline $\mathbf{2 0 1 4}$ & $\mathbf{2 0 1 5}$ & $\mathbf{2 0 1 6}$ & $\mathbf{2 0 1 7}$ & $\mathbf{2 0 1 8}$ \\
\hline 62,33 & 54,31 & 44,11 & 54,35 & 71 \\
\hline
\end{tabular}

Tabela 16 - Preço bruto do crude de referência, tipo brent (em dólares por barril)

- K - Taxa de Câmbio: medida pelo valor anual médio do câmbio comercial para venda, em reais por dólar, divulgado pelo BCB (Banco Central Brasileiro)

\begin{tabular}{|l|l|l|l|l|l|}
\hline $\mathbf{2 0 1 3}$ & $\mathbf{2 0 1 4}$ & $\mathbf{2 0 1 5}$ & $\mathbf{2 0 1 6}$ & $\mathbf{2 0 1 7}$ & $\mathbf{2 0 1 8}$ \\
\hline 2,16 & 2,35 & 3,33 & 3,49 & 3,19 & 3,65 \\
\hline
\end{tabular}

Tabela 17 - Valor anual médio do câmbio comercial para venda (em reais por dólar)

- N - Consumo Mundial de Petróleo: Medido em milhares de barris de petróleo equivalentes consumidos mundialmente por dia, divulgado pela BP Statistical Review of Word Energy

\begin{tabular}{|l|l|l|l|l|l|}
\hline $\mathbf{2 0 1 3}$ & $\mathbf{2 0 1 4}$ & $\mathbf{2 0 1 5}$ & $\mathbf{2 0 1 6}$ & $\mathbf{2 0 1 7}$ & $\mathbf{2 0 1 8}$ \\
\hline 92.276 & 93.194 & 95.048 & 96.737 & 98.406 & 99.846 \\
\hline
\end{tabular}

Tabela 18 - Consumo Mundial de Petróleo (em milhares de barris de petróleo equivalentes consumidos mundialmente por dia)

- P - Importação Brasileira de Petróleo: Medida da quantidade de petróleo importada pelo Brasil em barris equivalente de petróleo no ano, divulgada pela ANP

\begin{tabular}{|l|l|l|l|l|l|}
\hline $\mathbf{2 0 1 3}$ & $\mathbf{2 0 1 4}$ & $\mathbf{2 0 1 5}$ & $\mathbf{2 0 1 6}$ & $\mathbf{2 0 1 7}$ & $\mathbf{2 0 1 8}$ \\
\hline 147.838 .380 & 144.151 .877 & 118.285 .942 & 65.178 .875 & 54.475 .175 & 67.961 .180 \\
\hline
\end{tabular}

Tabela 19 - Quantidade de petróleo importada pelo Brasil

(em barris equivalente de petróleo no ano) 
- R - Fontes Renováveis de Energia: Medida pela Oferta Interna de Energia (OIE) em milhares de TEP (Tonelada Equivalente de Petróleo), divulgado pelo Ministério de Minas e Energia (MME)

\begin{tabular}{|l|l|l|l|}
\hline $\mathbf{2 0 1 5}$ & $\mathbf{2 0 1 6}$ & $\mathbf{2 0 1 7}$ & $\mathbf{2 0 1 8}$ \\
\hline 123.668 & 125.345 & Não há dados & Não há dados \\
\hline
\end{tabular}

Tabela 20 - Oferta Interna de Energia (OIE)

(em milhares de TEP - Tonelada Equivalente de Petróleo)

- T - Dependência externa brasileira de petróleo e seus derivados: medida em milhares de metros cúbicos por dia de petróleo e derivados, divulgado pela ANP

\begin{tabular}{|l|l|l|l|l|l|}
\hline $\mathbf{2 0 1 3}$ & $\mathbf{2 0 1 4}$ & $\mathbf{2 0 1 5}$ & $\mathbf{2 0 1 6}$ & $\mathbf{2 0 1 7}$ & $\mathbf{2 0 1 8}$ \\
\hline 12,3 & 7 & $-8,7$ & $-14,7$ & $-19,5$ & $-28,8$ \\
\hline
\end{tabular}

Tabela 21 - Dependência externa brasileira de petróleo e seus derivados (em milhares de metros cúbicos por dia de petróleo e derivados)

\subsection{MATRIZ DE IMPACTOS}

De posse dos indicadores e seus históricos, realizou-se um julgamento de impactos entre as variáveis, montando uma matriz de impactos cruzados apresentada na Tabela 22. Nessa matriz, cada variável apresentada na primeira coluna tem os impactos que causam nas demais representados nas demais colunas, respectivamente da variável A até a $\mathrm{T}$. Os julgamentos foram realizados numa escala de 0,5 em 0,5 , indo de $-3,0$ a $+3,0$, onde $-3,0$ representa o maior impacto negativo e $+3,0$ o maior impacto positivo.

\begin{tabular}{|c|c|c|c|c|c|c|c|c|c|c|c|c|c|c|c|c|c|c|c|c|}
\hline & & & & & & & & & & & & & $M$ & & & & $\mathrm{Q}$ & & & \\
\hline & & 0,0 & 0,0 & $\overline{0,0}$ & $\overline{5}$ & 0 & $\overline{0}$ & 0,5 & 5 & 0,0 & $\overline{0}$ & 2,0 & 3,0 & 0,0 & 1,0 & $\overline{2,0}$ & 2,0 & $\overline{0,5}$ & 0,5 & \\
\hline & & & 0 & $\overline{0}$ & 0 & 0 &, 5 & 0,5 & 0,5 & {$[0,0]$} & & ,0 &, 5 & & 5 & 0,5 & $\overline{5}$ & $0, c$ & & \\
\hline & & & & & & 0 & 5 & 0 & 0 & & 0 & 0 & 0 & & 0 & 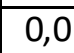 & , & , & & \\
\hline & & & כ, & & 2,0 & 0,5 & $-1,0$ & 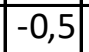 & , 5 & {$[0,0]$} & 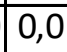 & 0,5 & 0,0 & 0,0 & 0,0 & ),5 & 0,5 & , ( & & \\
\hline & & & 0 & 0,0 & & 0 & 0 & 0 & 0 & 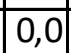 & 0 & 0 & 0 & 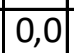 & 0,0 &, 0 & 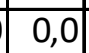 & & & \\
\hline & 0 & $\overline{0}$ & 0,0 & 1,0 & 2,0 & & 0 & 2,0 & 1,0 & 0,0 & $\overline{0,0}$ & 0,0 & 2,5 & \begin{tabular}{|l|}
0,0 \\
\end{tabular} & 2,0 & $-0,5$ & 1,0 & 1,0 & , , & \\
\hline & & & 0 & $\overline{0}$ & 0 & 0 & & 15 & 3,0 & 0,0 & $\overline{0}$ & 0,0 & 0 & $0,0 \mid$ & ,5] & $\overline{0} 0$ & ,0 & 1,0 & & \\
\hline & 0 & 0 & 0,0 & 0,0 & $\overline{0,0}$ & $\overline{0,0}$ & 0,0 & & 0,0 & 0,0 & $\overline{0,0}$ & 0,5 & $\overline{0,0}$ & 0,0 & 0,0 & $\overline{0,0}$ & 0,0 & 0,0 & D, ( & \\
\hline & & 0 & 0 & 5 & $\overline{0}$ & 0 & 3,0 & 0,5 & & 0 & 0 & $-1,0$ & 0 & 0,0 & 2,0 & 0,5 & .0 & $-0,5 \mid$ & & \\
\hline & 0 & 5 & 10 & 0,5 & 1,0 & 2,0 & $-0,5$ & 0,5 & 3,0 & & 0 & 0,5 & 2,0 & 3,0 & 2,5 & \begin{tabular}{|l|}
$-1,0$ \\
\end{tabular} & 1,0 & $2, \mathrm{C}$ & , 5 & \\
\hline & & 0 & 0 & 0 & 0 & 0 & ,5 & 0,0 & $-1,0$ & (c) & & 1,0 & 0,0 & 0,0 & 0 & \begin{tabular}{|l|}
$-1,0$ \\
\end{tabular} & 1,0 & 0,0 & ,0 & \\
\hline & 0,0 & 0 & 0,0 & 0,0 & 0,0 & $-1,0$ & $-1,5$ & 0,0 & $-0,5$ & 0,0 & 0,0 & & 1,0 & $\mid 0,0$ & $-0,5$ & 2,0 & $-1,0$ & 2,0 & 0,0 & \\
\hline & 0 & 0 & 0 & 0 & 3,0 & 0 & 0,0 & 2,0 & 3,0 & 0,0 & 0,0 & 0,5 & & 0,0 & 2,0 & \begin{tabular}{|l|}
$-1,0$ \\
\end{tabular} & 2,0 & $|-2,0|$ & , 0 & \\
\hline & 0, & 5 & 0 & 0,0 & 0,5 & 0,0 & 0,0 & 0,5 & 2,0 & 3,0 & 0,0 & 0,5 & 0,0 & & 1,0 & $-0,5$ & 0,5 & 0,5 & 1,0 & \\
\hline & & & 1 & 0,5 & 2,5 & 5 & $-1,0$ & 0,5 & 1,5 & 0,0 & 0,0 & 0,0 & 0,5 & 0,0 & & $-3,0$ & $-1,0$ & $-2,0$ & ,5 & \\
\hline & & $\overline{0}$ & 0 & $-0,5$ & $-0,5$ & 0 & 0,0 & 1,0 & $-1,5$ & 0,0 & 0,0 & 0,0 & 0,0 & \begin{tabular}{|l|}
0,0 \\
\end{tabular} & $\mid-2,0$ & & 0,0 & $-3,0$ & 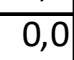 & \\
\hline C & 0,0 & 0 & 0,5 & $\overline{1,0}$ & 1,5 & 1,0 & $-2,0$ & 2,0 & 2,0 & 0,0 & 0,0 & 0,0 & 1,0 & 0,0 & $-0,5$ & 0,0 & & 0,0 & 0,0 & \\
\hline & & 1,0 & $-0,5$ & $-0,5$ & 3,0 & 2,0 & 0,0 & 0,5 & $-2,0$ & 0,0 & 0,0 & 0,0 & $-2,0$ & \begin{tabular}{|l|}
0,0 \\
\end{tabular} & $|-2,5|$ & $\mid-2,0$ & | כון & & 0,5 & \\
\hline & 0 , & 5 & 0,0 & 0,0 & $\overline{0,0}$ & 0,0 & 0,0 & 1,0 & 1,0 & 0,0 & 0,0 & 0,0 & 0,0 & 0,0 & 0,5 & 2,0 & $-0,5$ & 2,5 & & \\
\hline & & & 0 & & & & & 1,0 & 3,0 & 0,0 & 0,0 & 0,0 & 2,0 & & 이 & 3,0 & 23 & & & \\
\hline
\end{tabular}

Tabela 22 - Matriz de Impactos cruzados das variáveis 
Com os valores de impactos cruzados, é possível verificar o quanto uma determinada variável impacta nas demais e também o quanto ela é impactada pelas demais. O valor do impacto total que cada variável causa nas demais, representado aqui simplesmente pela palavra "impacto", é determinado pela soma algébrica da linha correspondente à variável na matriz de impactos cruzados. Já o valor do impacto total que cada variável sofre das demais, representado pela palavra "dependência", é determinado pela soma algébrica da coluna correspondente à variável nessa mesma matriz. A Tabela 23 apresenta os valores de impacto e dependência para cada variável.

\begin{tabular}{|c|r|r|}
\hline VARIÁVEL & IMPACTO & \multicolumn{1}{|c|}{ DEPENDÊCIA } \\
\hline A & 6,5 & 4,5 \\
\hline B & 0,0 & 10,0 \\
\hline C & 0,0 & 2,0 \\
\hline D & 1,0 & 2,5 \\
\hline E & 0,0 & 10,5 \\
\hline F & 9,0 & 8,0 \\
\hline G & $-5,5$ & $-3,0$ \\
\hline H & 1,5 & 8,0 \\
\hline I & 12,0 & 9,0 \\
\hline J & 17,0 & 3,0 \\
\hline K & 2,5 & 0,0 \\
\hline L & 0,5 & 0,5 \\
\hline M & 10,0 & 9,5 \\
\hline N & 8,5 & 3,0 \\
\hline O & $-2,5$ & 8,5 \\
\hline P & $-3,5$ & $-4,5$ \\
\hline Q & 6,5 & 5,5 \\
\hline R & $-16,0$ & 1,0 \\
\hline S & 9,0 & 3,0 \\
\hline T & 17,0 & $-7,5$ \\
\hline Ta & & \\
\hline
\end{tabular}

Tabela 23 - Valores de impactos e dependência para cada variável

Uma vez definidos os valores de impactos e dependências, constrói-se um gráfico de impacto versus dependência, com o impacto representado no eixo horizontal e a dependência no eixo vertical, conforme apresentado na Figura 1.

Para uma melhor visualização dos posicionamentos das variáveis com os valores médios de impacto e dependência das variáveis, traçaram-se duas linhas, uma horizontal (passando pela coordenada de valor médio do impacto) e outra vertical (passando pela coordenada de valor médio da dependência), dividindo a matriz em quatro quadrantes. 


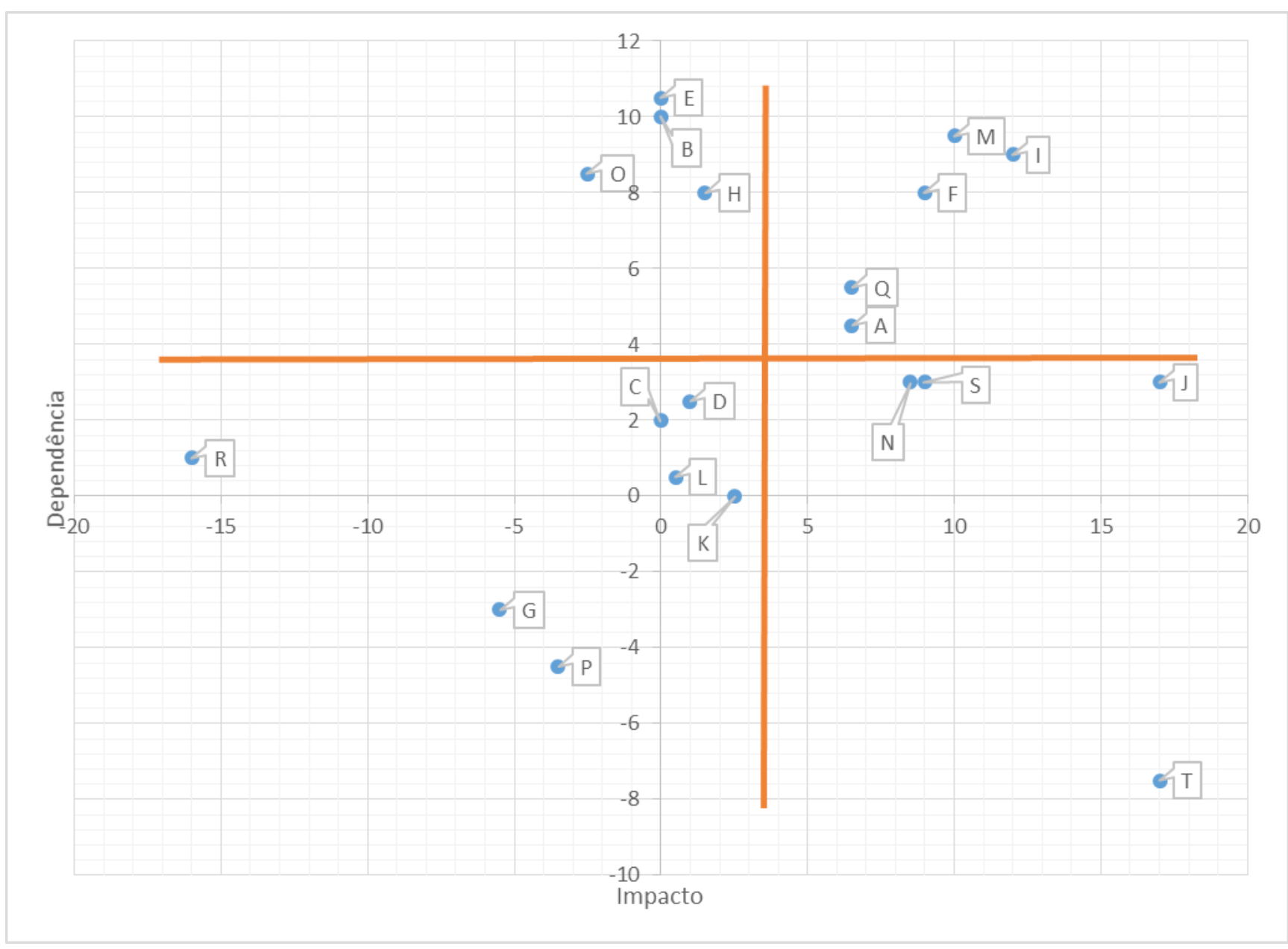

\begin{tabular}{|l|l|}
\hline \multicolumn{2}{|l|}{ LEGENDA } \\
\hline A & Viabilidade Técnica da Exploração do Pré-Sal \\
\hline B & Intelectual \\
\hline C & Segurança Ocupacional \\
\hline D & Segurança de Processo \\
\hline E & Meio Ambiente \\
\hline F & Reservas da Petrobras \\
\hline G & Saúde Financeira da Petrobras \\
\hline H & Relacionamento com o Mercado \\
\hline I & Capacidade de Investimento \\
\hline J & Preço do petróleo (Tipo Brent) \\
\hline K & Taxa de Câmbio \\
\hline L & Custo de extração \\
\hline M & Reservas provadas de petróleo no Brasil \\
\hline N & Consumo mundial de petróleo \\
\hline
\end{tabular}




\begin{tabular}{|l|l|}
\hline $\mathrm{O}$ & Capacidade efetiva de refino no Brasil \\
\hline $\mathrm{P}$ & Importação Brasileira de Petróleo \\
\hline $\mathrm{Q}$ & Exportação Brasileira de Petróleo \\
\hline $\mathrm{R}$ & Fontes renováveis de energia \\
\hline $\mathrm{S}$ & Crescimento econômico do Brasil \\
\hline $\mathrm{T}$ & Dependência externa brasileira de petróleo e seus derivados \\
\hline
\end{tabular}

Figura 1 - Gráfico Impacto versus Dependência

Desta forma, os quadrantes da matriz de impacto versus dependência representam quatro grandes grupos de variáveis:

- Quadrante superior direito - formado pelas variáveis A, F, I, M e Q, representa o conjunto de maior relevância, já que as variáveis apresentam valores elevados tanto de impacto, quanto de dependência, todos acima dos valores médios;

- Quadrante inferior direito - formado pelas variáveis J, N, S e T, representa um conjunto de relevância intermediária, pois as variáveis apresentam valores elevados de impacto (acima da média), porém valores baixos de dependência (abaixo da média);

- Quadrante superior esquerdo - formado pelas variáveis, B, E, H e O, representa também um conjunto de relevância intermediária, pois, apesar das variáveis apresentarem valores baixos de impacto (baixo da média), têm valores elevados de dependência (acima da média); e

- Quadrante inferior esquerdo - formado pelas variáveis C, D, G, K, L, P e R, representa o conjunto de menor relevância, uma vez que as variáveis apresentam valores baixos tanto de impacto, quanto de dependência, todos abaixo dos valores médios

A partir da análise de impacto versus dependência, vê-se que a construção de cenários prospectivos poderá focar nas variáveis localizadas no quadrante de maior relevância. Por outro lado, poderá desconsiderar as variáveis posicionadas no quadrante de baixa relevância, pois a exclusão não afetará significativamente o contexto analisado. Assim sendo, as variáveis C, D, G, K, L, P e R não serão consideradas na fase seguinte de construção de cenários prospectivos.

\subsection{CONSTRUÇÃO DE CENÁRIOS PROSPECTIVOS}

Desenvolvida por Fritz Zwick e aplicada a partir de 1942, a análise morfológica é uma técnica que busca configurar, de maneira sistemática, todas as situações possíveis para um dado sistema, através da combinação de diferentes estados dos parâmetros (características) desse sistema. Parte de uma situação dada e gera novas situações mediante reestruturações dessa situação inicial, produzindo um grande número de configurações alternativas. Está estruturada no desenvolvimento das seguintes etapas:

- Define-se o sistema da maneira mais precisa possível (Gomes, Costa, 2013).

- Analisa-se, descreve-se e identificam-se os parâmetros ou características básicas desse sistema.

- Examina-se cada parâmetro e define-se que estados (situações) independentes ele pode assumir.

- Introduzem-se restrições para eliminar combinações inconsistentes.

- Efetuam-se combinações alternativas entre os estados de cada parâmetro, respeitando as restrições estabelecidas.

Após a identificação das variáveis com maior peso (impacto versus dependência), configurações são criadas, segundo o conceito da análise morfológica, a fim de fornecer caminhos a serem analisados. Na Tabela 24 a seguir têm-se estas configurações. 


\begin{tabular}{|c|c|c|c|c|c|c|}
\hline \multirow{2}{*}{\multicolumn{2}{|c|}{ Variável }} & \multirow{2}{*}{ Indicador } & \multicolumn{4}{|c|}{ Configurações das Variáveis } \\
\hline & & & \multirow[b]{2}{*}{\begin{tabular}{|l|}
\multicolumn{1}{|c|}{ A } \\
Viabilidade muito \\
baixa em função de \\
dificuldades técnicas e \\
operacionais; $0 \leq \mathrm{x}<$ \\
30
\end{tabular}} & \multirow[b]{2}{*}{\begin{tabular}{|l|}
\multicolumn{1}{|c|}{ B } \\
Viabilidade baixa em \\
função de dificuldades \\
técnicas e restrições \\
ambientais; $30 \leq \mathrm{x}<$ \\
50
\end{tabular}} & \multirow[b]{2}{*}{\begin{tabular}{|l|}
\multicolumn{1}{|c|}{ C } \\
Viabilidade \\
moderada em função \\
de dificuldades \\
técnicas; $50 \leq \mathrm{x}<80$
\end{tabular}} & \multirow[b]{2}{*}{\begin{tabular}{|l}
\multicolumn{1}{|c}{ D } \\
Altamente \\
viável; \\
$80 \leq \mathrm{x} \leq 100$
\end{tabular}} \\
\hline A & $\begin{array}{l}\text { Viabilidade Tecnica } \\
\text { da Exploração do } \\
\text { Pré-Sal }\end{array}$ & $\begin{array}{l}\text { Percentual do } \\
\text { Sucesso } \\
\text { Exploratório }\end{array}$ & & & & \\
\hline $\mathrm{B}$ & Intelectual & $\begin{array}{l}\text { Investimento em } \\
\text { P\&D }\end{array}$ & $\begin{array}{l}\text { Baixo nível de } \\
\text { investimentos; } 0 \leq \mathrm{x}< \\
1,7\end{array}$ & $\begin{array}{l}\text { Moderado nível de } \\
\text { investimentos; } 1,7 \leq \mathrm{x} \\
<2\end{array}$ & $\begin{array}{l}\text { Alto nível de } \\
\text { investimentos; } 2 \leq \mathrm{x} \\
<2,5\end{array}$ & $\begin{array}{l}\text { Elevadíssimo nível de } \\
\text { investimentos; } x \geq \\
2,5\end{array}$ \\
\hline $\mathrm{E}$ & Meio Ambiente & $\begin{array}{l}\text { Emissão de Gases } \\
\text { de Efeito Estufa }\end{array}$ & $\begin{array}{l}\text { Baixo nível de } \\
\text { emissão; } 0 \leq \mathrm{x}<30\end{array}$ & $\begin{array}{l}\text { Moderado nível de } \\
\text { emissão; } 30 \leq \mathrm{x}<50\end{array}$ & $\begin{array}{l}\text { Alto nível de emissão; } \\
50 \leq \mathrm{x}<70\end{array}$ & $\begin{array}{l}\text { Elevadíssimo nível de } \\
\text { emissão; } x \geq 70\end{array}$ \\
\hline $\mathrm{F}$ & $\begin{array}{l}\text { Reservas da } \\
\text { Petrobras }\end{array}$ & $\begin{array}{l}\text { Volume das } \\
\text { Reservas }\end{array}$ & $\begin{array}{l}\text { Grande } \\
\text { desaceleração } \\
\text { na descoberta } \\
\text { de petróleo; } \\
0 \leq x<12 \\
\end{array}$ & $\begin{array}{l}\text { Moderada } \\
\text { desaceleração; } \\
12 \leq x<15\end{array}$ & $\begin{array}{l}\text { Moderado } \\
\text { crescimento; } \\
15 \leq \mathrm{x}<20\end{array}$ & $\begin{array}{l}\text { Descoberta de } \\
\text { campos } \\
\text { gigantes; } \\
x \geq 20\end{array}$ \\
\hline $\mathrm{H}$ & $\begin{array}{l}\text { Relacionamento com } \\
\text { o Mercado }\end{array}$ & $\mathrm{N}^{\circ}$ de Fornecedores & $\begin{array}{l}\text { Baixo relacionamento } \\
\text { com o mercado; } 0 \leq \mathrm{x} \\
<7\end{array}$ & $\begin{array}{l}\text { Moderado } \\
\text { relacionamento com o } \\
\text { mercado; } 7 \leq \mathrm{x}<11\end{array}$ & $\begin{array}{l}\text { Alto relacionamento } \\
\text { com o mercado; } 11 \leq \\
\mathrm{x}<13\end{array}$ & $\begin{array}{l}\text { Elevadíssimo } \\
\text { relacionamento com } \\
\text { o mercado; } x \geq 13\end{array}$ \\
\hline I & $\begin{array}{l}\text { Capacidade de } \\
\text { Investimento }\end{array}$ & Investimento & $\begin{array}{l}\text { Baixo nível de } \\
\text { investimentos; } 0 \leq \mathrm{x}< \\
25\end{array}$ & $\begin{array}{l}\text { Moderado nível de } \\
\text { investimentos; } 25 \leq \mathrm{x} \\
<50\end{array}$ & $\begin{array}{l}\text { Alto nível de } \\
\text { investimentos; } 50 \leq \mathrm{x} \\
<75\end{array}$ & $\begin{array}{l}\text { Elevadíssimo nível de } \\
\text { investimentos; } x \geq 75\end{array}$ \\
\hline $\mathbf{J}$ & $\begin{array}{l}\text { Preço do petróleo } \\
\text { (Tipo Brent) }\end{array}$ & $\begin{array}{l}\text { Preço médio no } \\
\text { mercado spot do } \\
\text { petróleo tipo Brent }\end{array}$ & $\begin{array}{l}\text { Baixo crescimento } \\
\text { econômico e com isso } \\
\text { pouco aumento de } \\
\text { demanda nos países } \\
\text { nãoOCDE; aumento } \\
\text { na } \\
\text { produção da OPEP, } \\
\text { rumando a } \\
\text { aproximadamente } \\
\text { metade do produzido } \\
\text { no mundo; sucesso no } \\
\text { desenvolvimento da } \\
\text { produção em reservas } \\
\text { de tight oil e betume } \\
\text { em } \\
\text { países não OPEP; } 0 \leq \\
x<75\end{array}$ & $\begin{array}{l}\text { Crescimento } \\
\text { econômico estável e } \\
\text { produção da } \\
\text { OPEP em } 70 \% \text { da } \\
\text { mundial; } 75 \leq x<100\end{array}$ & \begin{tabular}{|l|} 
Crescimento \\
econômico estável \\
nos \\
países não OCDE; \\
produção da OPEP \\
em cerca de $40 \%$ da \\
mundial; sucesso no \\
desenvolvimento da \\
produção em \\
reservas de tight oil e \\
betume em países \\
não OPEP; \\
$100 \leq \mathrm{x}<140$
\end{tabular} & $\begin{array}{l}\text { Aumento expressivo } \\
\text { na } \\
\text { demanda dos países } \\
\text { não OCDE; } \\
\text { produção da OPEP } \\
\text { limita-se a } 40 \% \text { da } \\
\text { mundial até } 2040 ; \\
\text { desenvolvimento da } \\
\text { produção em } \\
\text { reservas de tight oil e } \\
\text { betume em países } \\
\text { não OPEP } \\
\text { considerado } \\
\text { abaixo do previsto; } \\
\text { x } \geq 140\end{array}$ \\
\hline M & $\begin{array}{l}\text { Reservas provadas } \\
\text { de petróleo no Brasil }\end{array}$ & $\begin{array}{l}\text { Bilhões de barris de } \\
\text { petróleo nas } \\
\text { reservas provadas } \\
\text { em território } \\
\text { nacional }\end{array}$ & $\begin{array}{l}\text { Grande desaceleração } \\
\text { na descoberta de } \\
\text { petróleo; } \\
0 \leq x<12\end{array}$ & $\begin{array}{l}\text { Moderada } \\
\text { desaceleração; } \\
12 \leq x<15\end{array}$ & $\begin{array}{l}\text { Moderado } \\
\text { crescimento; } \\
15 \leq x<20\end{array}$ & $\begin{array}{l}\text { Descoberta de } \\
\text { campos gigantes; } \\
x \geq 20\end{array}$ \\
\hline $\mathrm{N}$ & $\begin{array}{l}\text { Consumo mundial de } \\
\text { petróleo }\end{array}$ & $\begin{array}{l}\text { Milhares de barris } \\
\text { de petróleo } \\
\text { consumidos } \\
\text { mundialmente a cada } \\
\text { dia }\end{array}$ & $\begin{array}{l}\text { Expressiva redução } \\
\text { do } \\
\text { consumo mundial em } \\
\text { função de elevados } \\
\text { investimentos em } \\
\text { fontes } \\
\text { renováveis; } 0 \leq \mathrm{x}<91\end{array}$ & $\begin{array}{l}\text { Expressiva } \\
\text { desaceleração do } \\
\text { consumo; } 91 \leq x<93\end{array}$ & $\begin{array}{l}\text { Continuidade nos } \\
\text { níveis de } \\
\text { desaceleração atuais; } \\
93 \leq x<95\end{array}$ & $\begin{array}{l}\text { Crescimento } \\
\text { moderado; } \\
x \geq 95\end{array}$ \\
\hline $\mathrm{O}$ & $\begin{array}{l}\text { Capacidade efetiva } \\
\text { de refino no Brasil }\end{array}$ & \begin{tabular}{|l|} 
Capacidade total \\
efetiva de refino no \\
Brasil, em milhares \\
de barris por dia. \\
\end{tabular} & $\begin{array}{l}\text { Baixa capacidade de } \\
\text { refino; } 0 \leq \mathrm{x}<2,1\end{array}$ & $\begin{array}{l}\text { Moderada capacidade } \\
\text { de refino; } 2,1 \leq \mathrm{x}< \\
2,25\end{array}$ & $\begin{array}{l}\text { Alta capacidade de } \\
\text { refino; } 2,25 \leq \mathrm{x}<2,9\end{array}$ & $\begin{array}{l}\text { Elevadíssima } \\
\text { capacidade de } \\
\text { refino; } x \geq 2,9\end{array}$ \\
\hline Q & $\begin{array}{l}\text { Exportação } \\
\text { Brasileira de } \\
\text { Petróleo }\end{array}$ & $\begin{array}{l}\text { Quantidade de } \\
\text { petróleo exportado } \\
\text { pelo Brasil, em mil } \\
\text { barris por dia. }\end{array}$ & $\begin{array}{l}\text { Elevada redução } \\
\text { da exportação } \\
\text { do volume de } \\
\text { óleo; } \\
0 \leq x<150 \\
\end{array}$ & $\begin{array}{l}\text { Desaceleração } \\
\text { da exportação } \\
\text { do volume de } \\
\text { óleo; } \\
150 \leq x<300 \\
\end{array}$ & $\begin{array}{l}\text { Pequeno } \\
\text { acréscimo da } \\
\text { exportação; } \\
300 \leq x<500\end{array}$ & $\begin{array}{l}\text { Elevado } \\
\text { acréscimo da } \\
\text { exportação; } \\
x \geq 500\end{array}$ \\
\hline $\mathrm{S}$ & $\begin{array}{l}\text { Crescimento } \\
\text { econômico do Brasil }\end{array}$ & $\begin{array}{l}\text { Variação percentual } \\
\text { real do produto } \\
\text { interno bruto (PIB) } \\
\text { brasileiro }\end{array}$ & $\begin{array}{l}\text { Desaceleração } \\
\text { acentuada da } \\
\text { economia; } \\
0 \leq \mathrm{x}<7\end{array}$ & $\begin{array}{l}\text { Crescimento } \\
\text { moderado; } \\
7 \leq x<8\end{array}$ & $\begin{array}{l}\text { Crescimento } \\
\text { Elevado; } \\
8 \leq \mathrm{x}<10\end{array}$ & $\begin{array}{l}\text { Crescimento } \\
\text { muito elevado; } \\
x \geq 10\end{array}$ \\
\hline $\mathrm{T}$ & $\begin{array}{l}\text { Dependência externa } \\
\text { brasileira de petróleo } \\
\text { e seus derivados }\end{array}$ & $\begin{array}{l}\text { Dependência } \\
\text { externa brasileira de } \\
\text { petróleo e seus } \\
\text { derivados, em mil m³ } \\
\text { por dia }\end{array}$ & $\begin{array}{l}\text { Importação } \\
\text { elevada, } \\
\text { consumo } \\
\text { elevado, } \\
\text { produção baixa; } \\
x>2\end{array}$ & $\begin{array}{l}\text { Importação } \\
\text { elevada, } \\
\text { consumo estável } \\
\text { e produção } \\
\text { baixa; } \\
0<\mathrm{x} \leq 2\end{array}$ & $\begin{array}{l}\text { Importação } \\
\text { baixa, consumo } \\
\text { estável e } \\
\text { produção } \\
\text { estável; } \\
-4<x \leq 0\end{array}$ & $\begin{array}{l}\text { Importação } \\
\text { baixa, consumo } \\
\text { estável e } \\
\text { produção } \\
\text { elevada; } \\
x \leq-4\end{array}$ \\
\hline
\end{tabular}

Tabela 24 - Configurações das variáveis selecionadas 
Após a análise das configurações, cenários foram identificados, permitindo que ações estratégicas fossem desenvolvidas para colocar a empresa numa posição privilegiada no mercado. A Tabela 25 apresenta a legenda de cores para identificação dos cenários. A Tabela 26 apresenta os cenários desejado (OURO NEGRO) e indesejado (OURO MALDITO). A Tabela 27 apresenta o cenário provável (MAL NECESSÁRIO).

\begin{tabular}{|l|l|l|}
\hline \multirow{2}{*}{ CENÁRIOS } & DESEJADO (OURO NEGRO) & \\
\cline { 2 - 3 } & INDESEJADO (OURO MALDITO) & \\
\cline { 2 - 3 } & PROVÁVEL (MAL NECESSÁRIO) & \\
\hline
\end{tabular}

Tabela 25 - Legenda

\begin{tabular}{|c|c|c|c|c|c|c|}
\hline & & nários desejad & (OURC & O) e indese & OURO M & ITO) \\
\hline \multirow{2}{*}{\multicolumn{2}{|c|}{ Variável }} & \multirow{2}{*}{ Indicador } & \multicolumn{4}{|c|}{ Configurações das Variáveis } \\
\hline & & & $\mathbf{A}$ & B & C & D \\
\hline A & $\begin{array}{l}\text { Viabilidade Técnica } \\
\text { da Exploração do } \\
\text { Pré-Sal } \\
\end{array}$ & \begin{tabular}{|l|} 
Percentual do \\
Sucesso \\
Exploratório \\
\end{tabular} & $0 \leq x<30$ & $30 \leq x<50$ & $50 \leq x<80$ & $\begin{array}{l}80 \leq \mathrm{x} \leq 100 \\
+\mathrm{GG} 22: \mathrm{G} 30\end{array}$ \\
\hline B & Intelectual & $\begin{array}{l}\text { Investimento em } \\
\mathrm{P} \& \mathrm{D}\end{array}$ & $0 \leq x<1,7$ & $1,7 \leq x<2$ & $2 \leq x<2,5$ & $x \geq 2,5$ \\
\hline $\mathrm{E}$ & Meio Ambiente & $\begin{array}{l}\text { Emissão de Gases } \\
\text { de Efeito Estufa }\end{array}$ & $0 \leq x<30$ & $30 \leq x<50$ & $50 \leq x<70$ & $x \geq 70$ \\
\hline $\mathrm{F}$ & $\begin{array}{l}\text { Reservas da } \\
\text { Petrobras }\end{array}$ & $\begin{array}{l}\text { Volume das } \\
\text { Reservas }\end{array}$ & $0 \leq x<12$ & $12 \leq x<15$ & $15 \leq x<20$ & $x \geq 20$ \\
\hline $\mathrm{H}$ & $\begin{array}{l}\text { Relacionamento com } \\
\text { o Mercado }\end{array}$ & $\mathrm{N}^{\mathrm{o}}$ de Fornecedores & $0 \leq x<7$ & $7 \leq x<11$ & $11 \leq x<13$ & $x \geq 13$ \\
\hline I & $\begin{array}{l}\text { Capacidade de } \\
\text { Investimento }\end{array}$ & Investimento & $0 \leq x<25$ & $25 \leq x<50$ & $50 \leq x<75$ & $x \geq 75$ \\
\hline $\mathrm{J}$ & $\begin{array}{l}\text { Preço do petróleo } \\
\text { (Tipo Brent) }\end{array}$ & \begin{tabular}{|l} 
Preço médio no \\
mercado spot do \\
petróleo tipo Brent
\end{tabular} & $0 \leq x<75$ & $75 \leq x<100$ & $100 \leq x<140$ & $x \geq 140$ \\
\hline M & $\begin{array}{l}\text { Reservas provadas } \\
\text { de petróleo no Brasil }\end{array}$ & \begin{tabular}{|l|} 
Bilhões de barris de \\
petróleo nas \\
reservas provadas \\
em território \\
nacional
\end{tabular} & $0 x<12$ & $12 \leq x<15$ & $15 \leq x<20$ & $x \geq 20$ \\
\hline $\mathrm{N}$ & $\begin{array}{l}\text { Consumo mundial de } \\
\text { petróleo }\end{array}$ & $\begin{array}{l}\text { Milhares de barris } \\
\text { de petróleo } \\
\text { consumidos } \\
\text { mundialmente a cada } \\
\text { dia }\end{array}$ & $\leq x<91$ & $91 \leq x<93$ & $93 \leq x<95$ & $x \geq 95$ \\
\hline $\mathrm{O}$ & $\begin{array}{l}\text { Capacidade efetiva } \\
\text { de refino no Brasil }\end{array}$ & $\begin{array}{l}\text { Capacidade total } \\
\text { efetiva de refino no } \\
\text { Brasil, em milhares } \\
\text { de barris por dia. }\end{array}$ & $0 \leq x<2,1$ & $2,1 \leq x<2,25$ & $2,25 \leq x<2,9$ & $x \geq 2,9$ \\
\hline Q & $\begin{array}{l}\text { Exportação } \\
\text { Brasileira de } \\
\text { Petróleo }\end{array}$ & $\begin{array}{l}\text { Quantidade de } \\
\text { petróleo exportado } \\
\text { pelo Brasil, em mil } \\
\text { barris por dia. } \\
\end{array}$ & $0 \leq x<150$ & $150 \leq x<300$ & $300 \leq x<500$ & $x \geq 500$ \\
\hline $\mathrm{S}$ & $\begin{array}{l}\text { Crescimento } \\
\text { econômico do Brasil }\end{array}$ & $\begin{array}{l}\text { Variação percentual } \\
\text { real do produto } \\
\text { interno bruto (PIB) } \\
\text { brasileiro }\end{array}$ & $0 \leq x<7$ & $7 \leq x<8$ & $8 \leq x<10$ & $x \geq 10$ \\
\hline $\mathrm{T}$ & $\begin{array}{l}\text { Dependência externa } \\
\text { brasileira de petróleo } \\
\text { e seus derivados }\end{array}$ & \begin{tabular}{|l|} 
Dependência \\
externa brasileira de \\
petróleo e seus \\
derivados, em mil m³ \\
por dia
\end{tabular} & $x>2$ & $0<x \leq 2$ & $-4<x \leq 0$ & $x \leq-4$ \\
\hline
\end{tabular}

Tabela 26 - Cenários desejado (OURO NEGRO) e indesejado (OURO MALDITO 
Cenário provável (MAL NECESSÁRIO).

\begin{tabular}{|c|c|c|c|c|c|c|}
\hline \multirow{2}{*}{\multicolumn{2}{|c|}{ Variável }} & \multirow{2}{*}{ Indicador } & \multicolumn{4}{|c|}{ Configurações das Variáveis } \\
\hline & & & $\mathbf{A}$ & B & C & D \\
\hline A & $\begin{array}{l}\text { Viabilidade Técnica } \\
\text { da Exploração do } \\
\text { Pré-Sal }\end{array}$ & $\begin{array}{l}\text { Percentual do } \\
\text { Sucesso } \\
\text { Exploratório }\end{array}$ & $0 \leq x<30$ & $30 \leq x<50$ & $50 \leq x<80$ & $\begin{array}{l}80 \leq x \leq 100 \\
+\mathrm{GG} 22: \mathrm{G} 30\end{array}$ \\
\hline B & Intelectual & $\begin{array}{l}\text { Investimento em } \\
\text { P\&D }\end{array}$ & $0 \leq x<1,7$ & $1,7 \leq x<2$ & $2 \leq x<2,5$ & $x \geq 2,5$ \\
\hline $\mathrm{E}$ & Meio Ambiente & $\begin{array}{l}\text { Emissão de Gases } \\
\text { de Efeito Estufa }\end{array}$ & $0 \leq x<30$ & $30 \leq x<50$ & $50 \leq x<70$ & $x \geq 70$ \\
\hline $\mathrm{F}$ & $\begin{array}{l}\text { Reservas da } \\
\text { Petrobras } \\
\end{array}$ & $\begin{array}{l}\text { Volume das } \\
\text { Reservas }\end{array}$ & $0 \leq x<12$ & $12 \leq x<15$ & $15 \leq x<20$ & $x \geq 20$ \\
\hline $\mathrm{H}$ & $\begin{array}{l}\text { Relacionamento com } \\
\text { o Mercado }\end{array}$ & $\mathrm{N}^{\mathrm{o}}$ de Fornecedores & $0 \leq x<7$ & $7 \leq x<11$ & $11 \leq x<13$ & $x \geq 13$ \\
\hline $\mathrm{I}$ & $\begin{array}{l}\text { Capacidade de } \\
\text { Investimento }\end{array}$ & Investimento & $0 \leq x<25$ & $25 \leq x<50$ & $50 \leq x<75$ & $x \geq 75$ \\
\hline $\mathrm{J}$ & $\begin{array}{l}\text { Preço do petróleo } \\
\text { (Tipo Brent) }\end{array}$ & \begin{tabular}{|l} 
Preço médio no \\
mercado spot do \\
petróleo tipo Brent
\end{tabular} & $0 \leq x<75$ & $75 \leq x<100$ & $100 \leq x<140$ & $x \geq 140$ \\
\hline M & $\begin{array}{l}\text { Reservas provadas } \\
\text { de petróleo no Brasil }\end{array}$ & $\begin{array}{l}\text { Bilhões de barris de } \\
\text { petróleo nas } \\
\text { reservas provadas } \\
\text { em território } \\
\text { nacional }\end{array}$ & $0 \leq x<12$ & $12 \leq x<15$ & $15 \leq x<20$ & $x \geq 20$ \\
\hline $\mathrm{N}$ & $\begin{array}{l}\text { Consumo mundial de } \\
\text { petróleo }\end{array}$ & $\begin{array}{l}\text { Milhares de barris } \\
\text { de petróleo } \\
\text { consumidos } \\
\text { mundialmente a cada } \\
\text { dia }\end{array}$ & $0 \leq x<91$ & $91 \leq x<93$ & $93 \leq x<95$ & $x \geq 95$ \\
\hline $\mathrm{O}$ & $\begin{array}{l}\text { Capacidade efetiva } \\
\text { de refino no Brasil }\end{array}$ & $\begin{array}{l}\text { Capacidade total } \\
\text { efetiva de refino no } \\
\text { Brasil, em milhares } \\
\text { de barris por dia. } \\
\end{array}$ & $0 \leq x<2,1$ & $2,1 \leq x<2,25$ & $2,25 \leq x<2,9$ & $x \geq 2,9$ \\
\hline Q & $\begin{array}{l}\text { Exportação } \\
\text { Brasileira de } \\
\text { Petróleo }\end{array}$ & $\begin{array}{l}\text { Quantidade de } \\
\text { petróleo exportado } \\
\text { pelo Brasil, em mil } \\
\text { barris por dia. }\end{array}$ & $0 \leq x<150$ & $150 \leq x<300$ & $300 \leq x<500$ & $x \geq 500$ \\
\hline $\mathrm{S}$ & $\begin{array}{l}\text { Crescimento } \\
\text { econômico do Brasil }\end{array}$ & \begin{tabular}{|l|} 
Variação percentual \\
real do produto \\
interno bruto (PIB) \\
brasileiro
\end{tabular} & $0 \leq x<7$ & $7 \leq x<8$ & $8 \leq x<10$ & $x \geq 10$ \\
\hline $\mathrm{T}$ & $\begin{array}{l}\text { Dependência externa } \\
\text { brasileira de petróleo } \\
\text { e seus derivados }\end{array}$ & \begin{tabular}{|l|} 
Dependência \\
externa brasileira de \\
petróleo e seus \\
derivados, em mil m³ \\
por dia
\end{tabular} & $x>2$ & $0<x \leq 2$ & $-4<x \leq 0$ & $x \leq-4$ \\
\hline
\end{tabular}

Tabela 27 - Cenário provável (MAL NECESSÁRIO).

\subsection{PLANEJAMENTO DE AÇõES ESTRATÉGICAS}

Por meio da análise dos cenários, recomenda-se que a Petrobras:

- invista na associação com outros grandes players da indústrias, de modo a:

- reduzir a necessidade de investimentos próprios;

- diluir riscos;

- fomente a disciplina de capital, para redução do endividamento;

- faça parcerias com centros tecnológicos visando a inovação;

- realize um gestão de portfolio em linha com seu core (pré-sal); 
- busque redução de seus custos operacionais e administrativos;

- capitalize os recursos descobertas no menor prazo possível;

- busque investir em outras fontes em associação aos investimentos em seu core;

- eleve seu rating.

\section{CONCLUSÃO}

Este artigo vem corroborar a aplicabilidade do conceito da prospecção de cenários na maior indústria nacional no setor de petróleo. Mais abrangente que os resultados obtidos no estudo em questão, o artigo propõe a reflexão quanto às diferentes possibilidades de futuro, e, por sua vez, o quanto o presente pode influenciar o futuro. O cenário prospectivo para esta indústria apresenta variáveis ainda bastante sensíveis que não estão no foco da política energética nacional, embora as recomendações estratégicas derivadas do cenário provável estejam em linha com vigentes no atual plano estratégico da Petrobras.

Importante ressaltar que os investimentos hoje em andamento no Brasil possuem prazo de maturação muito acima do utilizado para o planejamento de cenários neste artigo. Assim, deve-se considerar o aspecto tático no momento de estruturação das operações baseadas no estudo realizado.

\section{REFERÊNCIAS BIBLIOGRÁFICAS}

[1] AGÊNCIA NACIONAL DE PETRÓLEO, GÁS NATURAL E BIOCOMBUTÍVEIS. Oferta permanente passa a contar com 600 blocos e 14 áreas com acumulação marginais. Disponível em: < http://www.anp.gov.br/noticias/anp-e-p/5182-ofertapermanente-acumulacoes-marginais>. Acesso em: 28 de outubro de 2019.

[2] ALMEIDA, A. L.; MARICATO, J. M. Prospecção de cenários e monitoramento informacional como ferramentas de inteligência competitiva para o planejamento de políticas públicas no estado de Goiás. Informação e informação, v. 20, n. 3, p. 248 273, 2015.

[3] AMER, M.; DAIM, T. U.; JETTER, A. A review of scenario planning. Futures, v. 46, p. 23-40, 2013.

[4] ANDRADE, A. N. C.; GOMES, C. F. S. Cenários prospectivos para o setor da construção civil no Brasil e no Rio de Janeiro. In: Encontro Nacional de Engenharia de Produção, 37, 2017, Joinville, SC. Anais... Santa Catarina: ENEGEP, 2017.

[5] ASSIS, B. F. S. P.; PEREIRA, D. S.; MACHADO, L. G.; GOMES, C. F. S. Cenários prospectivos na aviação comercial brasileira. Revista GEINTEC, v. 7, n. 1, p. 36863700, 2017.

[6] AZEVEDO, A. W.; ARAÚJO, W. J.; DUARTE, E. N. Prospecção de cenário de maio de s para competências em informação como instrumento de inteligência competitiva. Revista de Ciência da Informação e Documentação, v. 8, n. 2, p. 42 - 68, 2017.

[7] BARRIZONTE, J. L. Q., BASTIDA, E. J. L. \& ALONSO, K. R. Planeación estratégica con enfoque prospectivo para la editorial "Universo Sur". Revista Universidad y Sociedad, v. 7, n. 3, p. 160-167, 2015.

[8] BLOIS, H. D. Planejamento em Empresa Automotiva: Um Estudo de Caso por Meio da Prospecção de Cenários. Revista de Administração IMED, v. 8, n. 1, p. 121-145, 2018. 
[9] CAIRNS, G; WRIGHT, G. Making scenario interventions matter: Exploring issues of power and rationality. Futures \& Foresight Science, v. 1, p. 1 - 14, 2018.

[10] CAVALCANTI, N. T.; COSTA JUNIOR, C. L.; GOMES, C. F. S. Análise de cenários prospectivos: um estudo sobre uma microempreendedora no ramo de doces em Niterói-RJ. In: Encontro Fluminense de Engenharia de Produção, 6, 2016, Niterói, RJ. Anais... Niterói: ENFEPro, 2016.

[11] CONSELHO NACIONAL DE POLÍTICA ENERGÉTICA. Resolução $n^{\circ}$ 9, de 9 maio de 2019. Estabelece diretrizes para a promoção da livre concorrência na atividade de refino no País. Disponível em: < http://www.mme.gov.br/documents/10584/126063519/Resolu \%C3\%A7\%C3\%A3o CNPE 9 2019.pdf/2798e864-be72-4ab3-912d-08f88d1e3704>. Acesso em: 28 de outubro de 2019.

[12] DOBIAS, P., EISLER, C. Scenario Set as a Representative of Possible Futures. Springer Proceedings in Complexity, p. 237-244, 2018.

[13] GODET, Michel. Método e cenários. Manual de prospectiva estratégica: da antecipação à ação. Lisboa: Publicações Dom Quixote, 1993.

[14] GOMES, C. F. S.; COSTA, H. G. Proposta do uso da visão prospectiva no processo multicritério de decisão. Relatórios de Pesquisa em Engenharia de Produção, v. 13, n. 8, p. 94- 114, 2013.

[15] MARCIAL, E. C; GRUMBACH, R. J. S. Cenários prospectivos: como construir um futuro melhor. Rio de Janeiro: FGV, 2002.

[16] MINISTÉRIO DE MINAS E ENERGIA. Ações nos Setores Elétrico, de Petróleo, Gás Natural e Biocombustíveis, e Mineral. Brasília: MME, 2019a.

[17] MINISTÉRIO DE MINAS E ENERGIA. Abastece Brasil. 2019b. Disponível em: $<$ http://www.mme.gov.br/web/guest/secretarias/petroleo-gas-natural-e-combustiveisrenovaveis/programas/abastece-brasil/noticias>. Acesso em: 28 de outubro de 2019.

[18] PETROBRAS. Comunicados ao mercado. Disponível em: $<$ https://www.investidorpetrobras.com.br/pt/resultados-e-comunicados/comunicadosao-mercado >. Acesso em: 28 de outubro de 2019.

[19] REIS, D. R.; VINCENZI, T. B.; PUPO, F. P. Técnicas de Prospecção: Um Estudo Comparativo. Revista de Administração Contemporânea, v. 20, n. 2, p. 135-153, 2016.

[20] ROHRBECK, R.; BATTISTELLA, C.; HUIZINGH, E. Corporate foresight: An emerging field with a rich tradition. Technological Forecasting and Social Change, 101, 1-9, 2015.

[21] SANSEVERINO, A. M.; GOMES, C. F. S.; BARCELOS, M. R. S. Cenários prospectivos para uma universidade pública. ENGEVISTA, V. 20, n.4, p.601-622, 2018.

[22] SCHWARTZ, P. A arte da visão de longo prazo. São Paulo: Best Seller, 2003.

[23] TRIBUNAL DE CONTAS DA UNIÃO. Desafios do Estado Brasileiro no Desenvolvimento do Setor de O\&G. Brasília: TCU, 2018.

[24] VIEIRA, C. et al. Mercado brasileiro de etanol: visão prospectiva de cenários. Relatórios de Pesquisa em Engenharia de Produção, v.14, n. 15, p.188-212, 2014. 
[25] WITT, T.; DUMEIER, M.; GELDERMANN, J. Combining scenario planning, energy system analysis, and multi-criteria analysis to develop and evaluate energy scenarios. Journal of Cleaner Production, v. 242, 2020. 